\title{
Modos de viver e fazer arte de pessoas em situação de rua
}

Antônio Vladimir Félix-Silva. Universidade Federal do Piauí.

Rita de Cássia Martins Sales. Centro de Atenção Psicossocial - São José de Mipibu (RN).

Gabriela Pinheiro Soares. Fundação Gregório Baremblitt; Instituto Félix Guattari.

\section{Resumo}

Este é um estudo acerca da arte de viver das pessoas em situação de rua. Trata-se de um recorte de uma pesquisa-intervenção realizada por meio de cartografias nômades, objetivando analisar processos de subjetivação em saúde mental que se configuram na produção desse modo de existência. Utiliza-se observação participante e diário de rua para a produção de dados, compondo, pesquisadores e sujeitos, as paisagens psicossociais para tensionar os dispositivos da rede de atenção psicossocial. Conclui-se que a vivência em situação de rua é um modo de fazer arte, ainda quando não se trata de resistência política ativa, haja vista a capacidade de sobrevir em extrema condição de vulnerabilidade social.

Palavras-chave: arte, processos de subjetivação, resistência.

\begin{abstract}
Ways of living and making art of people in homeless situation. This is a study about the art of living of the people in homeless situation. It is part of a research-intervention done through the nomads' cartography method, aiming to analyze the subjective processes in mental health that are configured in the production of this way of existence. It used participant and daily observation and street notes to the production of data, composing, researchers and subjects, psychosocial landscapes to tension the psychosocial care network devices. In conclusion, the experience of living on the streets is a way of making art, even when it is not active political resistance, given their ability to survive in extreme condition of social vulnerability.
\end{abstract}

Keywords: art, subjective processes, resistance.

\section{Resumen}

Modos de vida y arte de personas que viven en las calles. Este es un estudio sobre el arte de vivir de personas en la calle. Se trata de una investigación realizada por medio de cartografías nómadas, cuyo objetivo es analizar los procesos subjetivación en salud mental que se configuran en la producción de este modo de existencia. Se utiliza la observación participativa y el diario de calle, componiendo, investigadores y sujetos, los paisajes psicosociales para la producción de datos y para activar los dispositivos de la red de atención psicosocial. Se concluye que la vivencia en la calle es un modo de hacer arte, aun cuando no se trate de resistencia política activa, haya vista la capacidad de supervivencia en extrema condición de vulnerabilidad social.

Palabras clave: arte, procesos de subjetivación, resistencia. 
Cobertores sujos de restos de comida desbotados pelo tempo de um passado sem passado. Tempo suspenso. Sob esses cobertores homens e mulheres dormem como se não percebessem o sol que quase engole a terra. Prédios, carros, asfalto. Pessoas andam apressadas, desviando-se uma das outras, como num balé improvisado. Buzinas, ônibus, freios, prédios, prédios. Concreto. Nada concreto. Tudo móvel, rápido, líquido. Líquido de suor, saliva, urina, lágrima, líquido de esgoto, líquido da cerveja, do café, líquido da chuva. A mistura desses líquidos todos é o cheiro da rua, cheiro de tudo que é descartado, sujo, tudo o que não tem história. Os homens e mulheres dos cobertores desbotados sabem os segredos da rua, conhecem o cheiro da rua como se fosse o próprio cheiro do seu corpo, cheiro das coisas esquecidas. Nós, "de frente pro crime" (Bosco \& Blanc, 1975), sem pressa, vamos cada qual para nosso canto; olhamos o corpo no chão e fechamos a janela. E fica lá o corpo estendido no chão. Num cantinho de paisagem, tão desbotado quanto o seu cobertor.

Todavia, se, por um descuido, abrimos nossa janela e observamos, somos tomados pela diferença desses homens e mulheres, "a maioria negros [e pardos] que moram em lugar nenhum" (Baptista, 1999, p. 97). Uma unha enorme, pontuda, uma unha asquerosa destaca-se. Por causa da unha nos demoramos olhando aquele corpo, terceiro a arrebentar nossas vidraças. Ficamos sem a proteção daquela coisa invisível que nos separava. Essa unha parece querer penetrar nosso corpo, perfurar, invadir. Nós vemos nosso corpo com uma grande abertura, um umbigo do mundo furado, vísceras expostas, olhos, carnes, músculos, ossos. Tudo passa a sangrar em nosso corpo. O encontro com a diferença atravessa nosso corpo como flecha, como arma de guerra destruindo uma organização, uma estrutura pré-definida. Ficamos nós e nosso corpo sem órgãos (Deleuze \& Guattari, 1980/2012a). Quando nossa cidade-corpo é invadida por esses corpos máquina de guerra, nasce em nós um outro corpo, uma cidade-corpo sem fronteiras, sem muros, sem limites. Uma cidade-nômade a deslizar por todos os espaços. A unha é aqui utilizada como metáfora para a história, para a história das pessoas invisíveis que produzem, na rua, sua arte de viver. É um convite para pararmos, diante do corpo estendido no chão, e olharmos e deixarmos a unha penetrar nossas entranhas, nossas certezas, nossos medos. Viver a diferença.

Neste artigo apresentamos um estudo acerca dos modos de viver e fazer arte das pessoas em situação de rua, objetivando cartografar processos de subjetivação em saúde mental que se configuram na produção desse modo de existência. Durante um ano e meio, participamos de fóruns, seminários e audiências públicas organizados pelo Movimento Nacional da População de Rua - MNPR e instituições de direitos humanos. Em intervalos de até 15 dias, entre $19 \mathrm{~h}$ e $23 \mathrm{~h}$, aos domingos, fomos 10 vezes às ruas, acompanhando um grupo da Pastoral de Rua cuja composição varia de 10 a 20 leigos. Enquanto os leigos faziam ação cristã, nós nos fazíamos cartógrafos "por inscrição corporal, e não apenas por adesão teórica" (Pozzana, 2014, p. 42). Encontramos mais de 150 pessoas em situação de rua, entrevistamos 51 para a produção de informações e dados quantitativos. Delas, $8 \%$ são mulheres e $92 \%$ homens, $12 \%$ negros e $76 \%$ pardos. $45 \%$ declaram não apresentar problemas de saúde, mas $80 \%$ fazem uso de medicação. A medicalização da rua também é um sintoma da sociedade contemporânea.

Selecionamos, aqui, para análise cartográfica dos processos de subjetivação em saúde mental, apenas as narrativas que foram registradas em nossos diários de rua. Narrativas de corpos-pesquisadores que foram invadidos, tomados, penetrados pela metafórica unha das pessoas em situação de rua; desses corpos máquinas de guerra e as paisagens psicossociais nômades que compõem. Abertos ao campo dos afetos, "como estrangeiros visitantes de um território que não conhecemos, esse lugar desconhecido vai sendo explorado por olhares, escutas, sensibilidade aos odores, gostos e ritmos. Estando junto e participando daquilo que acontece naquela comunidade" (Barros \& Kastrup 2010, p. 61). Paisagens psicossociais nômades são os territórios de existência das pessoas em situação de rua, paisagens feitas de encontros, desencontros, paradas, recuos. Cada paisagem carrega em si a potência da diferença, na medida em que cada uma é, também, uma cartografia da cidade, seus espaços, cheiros, movimentos, singularmente vividos pelas pessoas em situação de rua.

A cartografia é um método de pesquisa-intervenção (Barros \& Kastrup 2010) que consiste na composição de paisagens psicossociais para acompanhar processos de subjetivação (Rolnik, 2006), fazendo "emergir realidades que não estavam "dadas", à espera de uma observação" e que podem estar ligadas à "dissolução do ponto de vista do observador" (Barros \& Barros, 2014, p. 175). Nesse modo de fazer pesquisa, o espaço da rua configura-se como uma clínica de passagem, peripatética (Lancetti, 2009). "O trabalho da clínica", como afirmam 
Passos e Benevides (2006, p. 91-92) "é acompanhar os movimentos afetivos da existência", cartografando os fluxos do desejo, as forças da vida e "os devires para fora de si".

Mattos e Ferreira (2004) assinalam que as pessoas que vivem em situação de rua são tipificadas como vagabundas, loucas, sujas, coitadinhas, perigosas, drogadas, sofredoras. Melo (2011) problematiza a genealogia desse fenômeno, que em algum momento histórico, foi reduzida à mendicância e à indigência, destacando que, nos últimos anos, a articulação entre os estudos focados nos trabalhos socioassistencial e das instituições e no protagonismo do MNPR têm contribuído para a superação de estigmas. Ao discutir os desafios para as políticas de saúde a partir da complexidade dessa população cujas pessoas que a constituem são tratadas como "descartáveis urbanos", Varanda e Adorno (2004, p. 58) destacam as nomeações pelas quais essas pessoas se identificam ou nomeiam umas às outras de acordo com as circunstâncias e conveniências: "maloqueiro", "trecheiros", "pardais", "pedreiros", "catadores", "sofredores de rua" (p. 5860). Todos esses autores questionam a produção da estigmatização, convergindo com a firmação de que se trata de "um grupo populacional heterogêneo, mas que possui em comum a pobreza extrema, os vínculos familiares interrompidos ou fragilizados e a inexistência de moradia convencional regular" (Silva, 2009. pp. 261262) cuja vivência em situação de rua é consequência do capitalismo, "um sistema econômico fundado na injustiça social, que produz a marginalidade, a pobreza, o povo da rua das cidades e o trabalhador sem terra dos campos" (Gadotti, 1997, p.12). Essa produção histórica e cultural se agrava na sociedade brasileira contemporânea, na qual "a invisibilidade social persiste e se institucionaliza através de equipamentos sociais que visam retirar as pessoas da rua, mas não oferecem reais possibilidades para a transformação de suas vidas" (Almeida et al., 2015, pp. 153-154).

Não obstante, ao compor o espaço esquizofrênico da cidade, essas pessoas, cujas falas são falas de uma multiplicidade prenhe de mundo, "não se subordinam de forma permanente à racionalidade hegemônica" (Santos, 2006, p. 114). A análise cartográfica aponta para processos de subjetivação em saúde mental cujo desejo opera por linhas molar, maleável e molecular (Deleuze \& Guattari, 2012a), ou seja, aponta para a coexistência de modos de viver das pessoas assujeitadas às condições de vulnerabilidade e de devir grupo sujeito
(Barros, 2013) a partir das vivências na rua e dos efeitos da relação com outros dispositivos. Iliche ${ }^{1}$ vivia em situação de rua e após um acontecimento que resultou um processo de subjetivação molecular (Deleuze \& Guattari, 2012a), ele passa a viver uma experiência de liderança relativa ao MNPR. O efeito que a relação com esse dispositivo produz é considerado por ele um modo de produzir saúde mental. Pensando com Paul Virilio (2011), podemos dizer: o pior de não "ser-no-mundo" pode provocar o melhor "de ser-no-corpo-territorial": "nascer na dor do confronto", nascer pelo meio (Deleuze \& Guattari, 2012a).

A arte de viver em situação de rua é a arte de apontar a unha asquerosa para os corpos distraídos que circulam pela cidade. É a arte de surpreender com sua vida nômade, sem espaços estriados, sem vidros, tijolos, paredes, sem cama, sem teto. É a arte de viver nas veias abertas da cidade, onde tudo é trânsito, passagem, fluxo. Arte de fazer arte dos artesãos de rua, que transformam o descartável em matéria-prima para o seu ofício; a arte de "fazer de tudo" como forma de ganhar a vida fazer capinagem, descarregar caminhões e dejetos da construção civil, vigiar carros - a arte de fazer arte como resistência política ativa, onde a vivência na rua se torna um vetor de corte nessa passagem. Corte no fluxo de passos, tempo, olhares vazios, chamando atenção para a monstruosidade de sua unha, produzindo experiências do fora (Levy, 2011), na realidade vivida, criando formas de viver em situação de rua como expressão dos processos de subjetivação em saúde mental.

Francisco, 23 anos, dois filhos, natural de uma das cidades da região metropolitana da cidade cartografada. É usuário de cocaína e de crack. Consegue ficar seis meses em casa. Fica em situação de rua para evitar que os filhos o vejam fazendo uso das substâncias. Ele não quer a toxicomania como exemplo para os filhos. $O$ corpo de Francisco é frágil, mas ele continua resistindo, resistindo ética, estética e politicamente. Seu modo de cuidar de si e do outro implica um processo de desindividução (Barros, 2013), configurando-se como processo de subjetivação em saúde mental que opera numa linha maleável (Deleuze \& Guattari, 2012a) e aponta em direção à "política de uma estética e de uma ética da existência" (Foucault, citado por Lavrador, 2012, pp. 408-409) Sua unha nos invade e nos faz ver a beleza desse corpo, corpo que foge para rua para não morrer, para não matar, para dar vida a outros corpos, seus filhos que, pequenos, talvez não possam suportar o padecimento daquele corpo viciadamente torpe. 


\section{Cartografias Nômades}

Primeira paisagem: Hospital Geral. Homens e mulheres dormem entre uma cigarreira, em marquises, em cadeiras da sala de espera. Algumas dessas pessoas estão circunstancialmente em situação de rua. Encontramos, por exemplo, pessoas que esperam consulta no Hospital Psiquiátrico, que fica próximo ao Hospital Geral ou nesse próprio estabelecimento. É o caso de Aparecida, 42 anos. Ela mora num bairro isolado, localizado na periferia da Cidade. Passava a noite nas proximidades do Hospital Geral no dia em que a encontramos. Esperava a consulta no Hospital Psiquiátrico, desejando um diagnóstico de transtorno mental que lhe assegure o Benefício de Prestação Continuada. Aparecida deseja que o psiquiatra produza uma segmentaridade para que seu desejo seja fixado numa linha dura, molar, contrária à produção de saúde mental. Ela espera na rua e, incidentalmente, faz a história da rua. Faz mostrar que a rua é múltipla, furando, com sua unha pontuda, a uniformidade do que se espera das pessoas que nela vivem.

Ainda nesse espaço, encontramos Joaquim, que vive em situação de rua há 20 anos. Do interior da Paraíba, veio para a cidade cartografada na condição de fugitivo. Praticou crime passional contra sua esposa. Diz-se uma pessoa tranquila, um bom marido, mas perdeu a cabeça. Traição ele não suporta. Declara: "(...) Peguei os dois na cama e dei uma facada nela". Respondeu processo por tentativa de homicídio. Não quer mais voltar para sua terra natal. Deseja aposentarse e alugar um lugar para morar. Joaquim, quando o encontramos, sentia dores no estômago. Dizia ter um tumor no intestino. Pediu nossa ajuda para os exames. Acompanhamos a articulação da PR para a consulta e realização dos exames, no período as equipes do Consultório na Rua estavam praticamente desativadas. Quinze dias depois, ele já havia feito o exame. Sentiase melhor. Os resultados não apresentaram nenhuma alteração no processo de saúde-doença de Joaquim. A proximidade do hospital e a convivência diária com os enfermos, segundo o médico, podia ter produzido essa percepção de enfermidade. A rua, para alguns, é lugar de passagem, é lugar do medo, da incerteza, da diferença. Para outros, contudo, é "casa", "abrigo", é o que acolhe quando não se tem para onde ir. A rua acolheu Joaquim, homem vindo de outras terras em busca de algo que não lembrasse passado. Ele produziu uma linha de fuga maleável, um porvir. Por não ter para onde ir, ele foi ficando na rua, rua sem cheiro, lembrança, rua que acolheu, calada, sua fuga. Rua-mulher que fez do seu ventre um lugar possível para Joaquim. Hoje, para ele, a rua tem história, tem lembrança, tem seus 20 anos de sonhos despedaçados. Os sintomas de Joaquim são efeitos do agenciamento dos processos de subjetivação em saúde mental e dos processos de semiotização do corpo marcado pela segmentaridade do desejo e pela fixação em uma identidade: "morador de rua".

Segunda paisagem: Uma das principais avenidas da cidade cartografada. Não há grande fluxo de pessoas diferentes na composição dessa paisagem psicossocial. No geral, encontrava-se lá uma população de 15 a 20 pessoas, a cada ida nossa ao campo. Num domingo posterior ao dia dos pais, Expedito, natural de uma cidade do interior do Ceará, há dez anos em situação de rua, disse: "(...) Esperei muito vocês aqui no dia dos Pais". Os encontros na cidade entre Expedito e os membros da pastoral tencionam afetos, contornos, territórios, pertencimentos. A Pastoral de Rua não como representação da família, mas como um arranjo familiar eventualmente improvisado. Não como uma espécie de família-útero, fechada, contudo, um espaço-tempo possível para amizade acontecer, amizade alimentada pela comida matéria oferecida pelos leigos da Pastoral de Rua e pelo alimento afeto produzido no encontro com o outro. A amizade faz com que a pessoa em situação de rua vá bater à porta de Sol, quando necessita mediação para marcar uma consulta médica ou para recuperar documentação, haja vista o fechamento do Centro de Referência Especializado para População em Situação de Rua - Centro Pop, durante o período da pesquisa. Amizade que pressupõe liberdade de dizer sim e de dizer não. Dizer sim, concordando com a reclamação por não ter ido à reunião no Centro de Atenção Psicossocial CAPS ou à consulta marcada pela Pastoral de Rua, sem a mediação do dispositivo Consultório na Rua. Dizer não ao convite para se submeter à internação em uma Comunidade Terapêutica ou para rezar, pedindo aos cartógrafos a volta do violão e dos instrumentos de percussão.

Inácio, oito anos em situação de rua. Gosta de surfar. Praticou o surfe durante 10 anos. Hoje, pinta prédios e casas. Inácio faz na rua sua arte, faz da rua, sua arte de viver. Quando o encontramos, Inácio arrumava seus cabelos com creme de pentear. A arte de viver nos pequenos gestos cotidianos, gestos improvisados na tessitura da rua, na contramão do espaço doméstico ordenado, privado. 
Terceira paisagem: Bairro onde acontece a feira mais movimentada da cidade. É um lugar de grande rotatividade de pessoas em situação de rua e onde se encontram mais expressivamente essa população. Abrigam-se em marquises. Em algumas, encontramos pessoas que se mantêm no mesmo local. É o caso de Zaqueu, há trinta anos vive nessa condição. Nesse bairro, também encontramos pessoas em situação de rua envolvidas com o uso de substâncias psicoativas. Sebastião, 63 anos, é um deles. É pai de santo e tem um filho. Chorava na primeira vez que o encontramos: "(...) Preciso de tratamento. Meu problema é álcool, álcool. Eu não estou conseguindo controlar". Perguntamos se ele sabia da existência do Consultório na Rua, que no início da pesquisa ainda se encontrava em atividade. Ele disse que não. Então, sugerimos que ele fosse ao Centro de Atenção Psicossocial de álcool e outras drogas - CAPS ad, que no início da pesquisa, ainda não funcionava $24 \mathrm{~h}$. Sebastião não sabia como chegar lá. Um companheiro em situação de rua se compromete em acompanhá-lo no dia seguinte. A rua costurando redes de apoio para a atenção à saúde mental. $A$ rua nos ensinando a riqueza do bordado e do colorido de suas linhas. A estética do cuidado bordada pelas mãos de unhas pontudas, bordada pelos homens dos cobertores desbotados que fazem da rua sua oficina, bordando uma arquitetura menor.

Bakita está em situação de rua há 13 anos. Tem três filhas, mas nenhuma delas vive na rua. $\mathrm{O}$ marido de uma das filhas é usuário de crack. Ela estava nervosa quando a encontramos: "(...) Eu preciso, eu quero me internar. Eu bebo desde os 10 anos de idade. Passo até seis meses sem beber, mas boto o pé na feira, bebo o primeiro gole, e pronto... Estou há três meses bebendo direto". Entramos em contato com uma das assistentes sociais do Hospital Psiquiátrico. Ela nos orientou a levar Bakita ao plantão. Bakita estava com medo, "lá só tem doido". Ela temia ser deixada sozinha durante a consulta e ser mandada de volta para a rua. Levamos Bakita ao plantão e a acompanhamos durante a consulta com o psiquiatra e seguimos em contato com a assistente social para acompanhar à distância como a paciente se encontrava. Bakita tem uma casa, a casa de uma das filhas. Entramos em contato com essa filha comunicando a internação da mãe, conforme solicitara Bakita, ao nos informar o número do celular da filha. Passamos também o endereço do CAPS-ad para que ela levasse Bakita após a alta do Hospital psiquiátrico. Dias depois da desinternação, a filha nos informou que a mãe tinha voltado para a rua. Bakita não consegue viver sem o álcool. Combustível para sua máquina desejante que, há muitos anos, tende a parar sem ele. Máquina que desaprendeu a funcionar com o combustível da vida de Bakita. Ela continua resistindo com seu desejo de viver. A rua acolhe suas incertezas, a rua espera, a rua a permite sonhar com uma vida possível, uma vida em que seu desejo possa mover essa e outras máquinas.

Quarta paisagem: Centro da cidade cartografada. Vivem lá, em geral, trabalhadores de rua, sobretudo, flanelinhas e pessoas que trabalham com materiais recicláveis. Uma delas é Lucas, 66 anos, há vinte anos em situação de rua. Trabalha com reciclagem e tem medo de dormir no Albergue Municipal. "Não quero ir para o Albergue, porque lá tem todo tipo de gente, e violência".

O complexo agenciamento dos processos de subjetivação faz com que Lucas associe violência a albergados. À diferença de Lucas, Moisés (comunicação pessoal, 13 de novembro de 2013) associa violência a quem deveria cuidar da segurança pública:

Quando vamos ao Albergue, já tem guardas com "banotes" ${ }^{2 "}$, quando procuramos onde dormir nas calçadas já tem guardas com "banotes", tá difícil até colocar os colchonetes debaixo das lojas, somos cidadãos iguais aos outros (...) Minha mulher entrou no Albergue porque ela tá com a carteira de trabalho. Fui roubado e estou só com o B.O, como não tenho documento com foto não entro lá.

A problemática da desigualdade econômica e da injustiça social que produzem a insegurança pública também se reproduz, durante o período da pesquisa, nos serviços de assistência à população de rua e na falta de atenção à saúde mental. Para algumas pessoas em situação de rua é mais seguro estar na rua do que em um estabelecimento como o Albergue Municipal, dispositivo de acolhimento noturno. À semelhança do CAPS ad, onde não entra quem está sob efeito de substâncias psicoativas, o Albergue fecha a porta para os sem documento, aos quais, em tese, deveria acolher. O Albergue entra na lógica da normatização, na lógica dos números, na lógica de Estado. "A organodisciplina da instituição" reproduzindo como polícia "a biorregulamentação" estatal (Foucault, 1997/2010, p. 210). Os nômades desconhecem essas lógicas todas, desconhecem os muros, as cercas, desconhecem limites. Preferem as ruas. Nas ruas, quando não há militarização dos guardas municipais ou da polícia, tudo é aberto, tudo dá lugar à passagem da vida. Lugar de passagem de vida foram também os nossos encontros com a Pastoral de Rua. A 
pesquisa-intervenção produziu afetação também nas pessoas que participam da Pastoral, as quais, afectadas (Espinosa, citado por Deleuze, 1981/2002), passaram a tensionar a rede de atenção psicossocial. Nós e nossas máquinas desejantes conectando as máquinas desejantes das pessoas da Pastoral de Rua.

No bairro da feira, os membros da pastoral (Sol, comunicação pessoal, 14 de setembro de 2014) encontraram uma mulher, com uma mala, chorando. Seria a primeira noite de Jaci em situação de rua. Tinha saído de casa após uma briga com a filha. Eles conversaram com ela e se colocaram à disposição para acompanhá-la de volta para casa; depois de argumentar e contra argumentar, Jaci aceitou. Então, eles foram com ela e entraram em contato com a filha, mediando a permanência da mulher com os familiares. De repente nós descobrimos uma pequena unha pontuda nascendo em nós, percebemo-nos capaz de furar, ainda que superficialmente, outros corpos. As pessoas da Pastoral de Rua conhecem muito bem a unha enorme e pontuda dos homens e mulheres de cobertores desbotados. $\mathrm{Na}$ pesquisa, conheceram a nossa, e se deixaram perfurar, construíram, conosco, uma cartografia, suas cartografias, outras cartografias.

\section{A Rua}

"Vivo nas ruas de um tempo onde dar nome é fornecer suspeitas. (...) Não me pergunte, pois, idade, estado civil, local de nascimento, filiação, pegadas do passado, nada, passado não (...) (Noll, 2008, p. 9). Não queremos falar em nome. Chega de nome, chega de rosto, chega de estado civil, chega de idade. Tudo isso nada nos diz. Se usamos nomes e idades, neste artigo, é apenas para pensar na multiplicidade das pessoas em situação de rua. Nenhum nome define, nenhuma idade, nenhum rosto. A rua é o mundo e o mundo é bricolagem de devires, é um corpo sem órgão, onde das mãos saem pés, dos pés saem cabeças, do coração saem vísceras, nas veias corre leite, corre urina, corre lágrimas.

Pagot (2012) concebe a rua como a mãe dos órfãos, mãe que cria, acolhe qualquer um; rua que não exclui ninguém, não se precipita em pré-julgamentos ou noção de norma - de onde vem, o que vai fazer, qual é a cor, qual é o sexo, qual é o nome. A rua apaga pegadas do passado, estabelecendo novas conexões, onde o doméstico, privado, familiar, vai dando lugar ao aberto, ao conectivo, como as artérias expostas da cidade, onde os encontros acontecem no sangue quente das ruas, na febre alta dos afetos. Essas relações vão tomando um caráter familiar (Morais, Paludo, \& Koller, 2010), familiar não no sentido de privado, fechado, uterino, entretanto, no sentido de acolher, de construir redes, de permitir certo contorno de territorialidade, pertencimento.

Antônio, natural de uma cidade da região metropolitana de São Paulo, vive em situação de rua, há um ano. Após o falecimento da mãe, ele ficou sem moradia, passando a morar no estacionamento de um hospital público. A sua família, agora, é plural, são os que vivem na rua com ele. De repente o calor do afeto para aquecer os corpos. Não obstante, a rua é também um espaço de muitas tensões, é um espaço do medo com sua foice de morte matada, como nos relata Moisés: "Tenho medo dessa copa, porque ouvi falar de um grupo de extermínio que vem para fazer a "limpeza" da cidade, tenho medo da gente morrer. Somos gente como qualquer um".

O sofrimento ético-político é o sofrimento provocado pelo obscurecimento, invisibilidade e estigmatização da pobreza, em especial das pessoas em situação de rua. Ele "retrata a vivência cotidiana das questões sociais dominantes em cada época histórica, especialmente a dor que surge da situação social de ser tratado como inferior, subalterno, sem valor, apêndice inútil da sociedade" (Sawaia, 2008, p. 104). Sawaia problematiza esse sofrimento e apresenta três formas de configuração do pensar, sentir e agir na dialética inclusão/exclusão das pessoas em situação de rua: $1^{a}$ - as pessoas que resistem à exclusão, que são os que estão cientes que são excluídas, querem sair dessa situação e desenvolvem potência de ação para sair, atuando "ao mesmo tempo na configuração da ação, significado e emoção, [emoções] coletivas e individuais" (p. 113); $2^{\text {a }}$ - as pessoas que são cientes da exclusão e querem sair, mas afirmam que não podem sair dessa condição de vulnerabilidade por que não há condições; $3^{\mathrm{a}}$ - as pessoas que não querem sair da situação de rua, relatando que acham bom viver assim. Sawaia (2008, p. 113) questiona:

Será que a afirmação de não querer sair da rua, é experiência de liberdade? Não seria a revelação da ruptura psicológica e social com a inclusão? Ou o abandono do direito de ser dono de sua própria liberdade, segundo expressão de Negri referindo-se a Espinosa (1993, p. 173)? Ou a cristalização de uma identidade negativa (Paugam, 1997)? Ou a autorrepressão de quem interioriza tão profundamente a servidão e a miséria que já nem sequer sabe desejar uma coisa quando ela lhe é oferecida (Baudrillard, 1995). 
Analisamos o complexo agenciamento dos processos de subjetivação em saúde mental para além da dialética exclusão/inclusão e encontramos mais de três modos de configuração nos modos de viver e fazer arte das pessoas em situação de rua. Realizamos a problematização de tal agenciamento, também, a partir da tradução e leitura que Deleuze faz do pensamento de Nietzsche e de Espinosa (Deleuze, 1962/1976; Deleuze, 1981/2002). Assim, a ordem da análise que se segue não implica necessariamente uma hierarquia, podendo coincidir ou não com as análises de pesquisas anteriores, mas também podendo apontar para uma multiplicidade de devires.

\section{Resistência como Potência de Ação}

Mateus fez curso de capacitação para trabalhar como padeiro. No curso, eles exigem que suas roupas e unhas estejam asseadas. Mateus desejava ser padeiro, pois gosta de mexer na massa do pão, sentir a massa do pão sendo moldada pelas suas mãos. Mateus vê arte nesse gesto cotidiano aparentemente banal de amassar o pão. O artista Mateus, todavia, não tinha lugar para lavarse adequadamente. Abandonar o curso foi inevitável. As unhas pontudas e sujas do artista Mateus o impediu de sonhar.

Paulo está há seis meses em situação de rua. Trabalha como catador de material reciclável. Vivia com a mãe até o falecimento dela, quando ficou sem moradia. Ele grita: "Viver na rua é uma desgraça!". Busca um emprego melhor que o possibilite sair da rua. O grito de Paulo lixa o céu seco, fazendo neve de poeira de unha, fazendo o tempo espichar feito lagartixa. O tempo para e Paulo atravessa. Paulo sempre vai atravessar, rua nenhuma segura as pernas de Paulo.

\section{O Virtual na Encruzilhada da Reatividade: Resistência como Força Passiva}

Samaritana, 39 anos, cinco filhos, uma ela denomina especial. O esposo era combatente. Recebia pensão por morte do esposo, mas deixou para a irmã cuidar de seus filhos. Samaritana está envolvida com o álcool e com o crack. Pede ajuda para deixar de usar essas substâncias. Trabalha como catadora: “(...) É só para manter o vício". A filha "especial" mora com a irmã e o cunhado. O maior medo de Samaritana é a filha ser estuprada pelo cunhado, porque ela já sofreu abuso sexual por parte dele. Sente também medo de dormir na rua: "(...) Eu me escondo nos cantos". Esconder-se nos cantos é uma forma de Samaritana pedir licença para dormir sem medo de ser acordada com o corpo quente sangrando fios de pólvora. Dormir torpe para nem ao menos sonhar que desaprendeu a sonhar.

\section{Viver na Rua como Modo de Vida. Território Rua Habitado}

Pedro, 68 anos. Está na rua há quatro anos. O encontramos, numa área do bairro onde, durante o dia, acontece a feira mais movimentada da cidade. Morou 18 anos na capital de um estado do Sudeste. Trabalhou dois anos e seis meses empalhando cadeiras. Sofreu acidente com serra elétrica e aposentou-se. Luta na justiça pelos direitos sociais trabalhistas. Está na cidade cartografada há 15 anos. Tem 13 filhos, três deles artesãos. Aprenderam a profissão do pai e orgulhamse disso. Um dos filhos é professor de artes. Quer que o pai vá morar com ele, no Sudeste. Pedro se recusa: não quer voltar. Sente-se bem com seu modo de vida e teme que, voltando, a ex-mulher voltará a persegui-lo, nos bares, como antes fazia. Assim como Pedro, Zaqueu, há 30 anos em situação de rua, prefere esse modo de vida. Trabalha, durante o dia, carregando caixas na feira, à noite, enquanto a feira dorme, ele dorme com ela na calçada. Às vezes seu irmão passa pela feira e o convida a voltar para casa. Zaqueu, contudo, prefere as calçadas e marquises, prefere o cheiro da rua e seu movimento: "Quando cheguei, aqui, nas ruas era tudo areia e calçada. Nada de asfalto". A rua passou junto à vida de Zaqueu. Seu pé pisando areia lembra passado. Marcas de uma cidade sob o rosto de Zaqueu. Gente a passar nas calçadas; cheias, vazias. Gente a passar por Zaqueu. $O$ céu escurece e ele permanece. A indústria produz novos carros e ele observa, parado, o movimento. $\mathrm{O}$ asfalto reflete a velhice no rosto de Zaqueu. $\mathrm{O}$ trânsito parado anuncia algo por vir. Zaqueu, certamente, sabe os segredos da cidade.

\section{Resultado das cartografias nômades}

A rua e a arquitetura da cidade "são máquinas enunciadoras. Elas produzem uma subjetivação parcial que se aglomera com outros agenciamentos de subjetivação" (Guattari, 1992/2012, p. 140). Nas nossas cartografais nômades, constatamos múltiplas configurações dos processos de subjetivação em saúde mental. Trata-se dos modos de viver e fazer arte em situação de rua de quem, ciente - ou não ciente - dos processos de inclusão e exclusão, escolhe viver a rua e 
na rua apontando para nossa necessidade de produzir com esse lugar uma relação ético-estético-política: resistência como força ativa, potência de vida e não só como potência de ação. Quando a potência de ação é investida de ideologia a ação pode cair no ativismo. Quando agir é sinônimo de potência de vida a vida flui. A vida como obra de arte.

\section{A Arte de Fazer Arte em Situação de Rua. Arte de Não Enquadrar-se}

Vidas que resistem esperneando. Vidas que mesmo em sua fraca saúde mental - em oposição à gorda saúde dominante pensada por Deleuze (1993/2011) teimam em resistir. Resistência, muitas vezes, doloridas, alucinógenas, delirantes, criativas. Resistência, por vezes, cheias de esperança. A força dos corpos desses personagens nômades é arte bruta. O exercício de sensibilidade com o mundo faz microfissuras no asfalto. Ao contrário de seguir um modelo normativo dado a priori, os personagens nômades caminham pelo deserto da experimentação de outras possibilidades de vida, a partir das composições afetivas no encontro com o outro. A força-desejo resistindo em ser capturada numa determinada lógica. Ao poder sobre a vida - biopoder - responde o poder da vida - biopotência. Aquilo que parecia completamente submetido à axiomática do capital, ou reduzido à mera passividade, a vida, aparece como fonte de valor, como potência viva que extrapola as economias de poder que pensavam pilotá-la (Pelbart, 2013). Morrer para dar lugar a outras formas de vida mais desejantes, menos assujeitadas. Viver na rua para resistir à morte do desejo. Viver na rua à espera de um corpo que nascerá, poderá, explodirá. O que a resistência extrai do corpo sem órgãos "são as forças, como diria Nietzsche, de uma vida mais ampla, mais ativa, mais afirmativa, mais rica em possibilidades", pois "quando o poder se torna biopoder, a resistência se torna poder da vida, poder-vital que vai além das espécies, dos meios e dos caminhos desse ou daquele diagrama (Deleuze, 1986/2005, pp. 124-125).

Aarão está há 15 anos em situação de rua. Artesão, trabalha com a confecção de objetos feitos de latinhas de alumínio. Além disso, descarrega caminhão, limpa para-brisas. Aarão tem a casa da avó para morar, mas prefere morar na rua para evitar desfazer-se das coisas de casa para vender e comprar crack. "(...) Eu bebo, eu fumo, e para minha família não ficar mais chateada comigo porque tenho medo de tirar alguma coisa deles, então prefiro a rua".
Em uma das idas a campo, observamos, no ponto de uma das principais avenidas da cidade, que um dos membros da pastoral estava fotografando, e um homem que está em situação de rua disse ao outro: “(...) Não deixe que ele tire sua foto. Você não sabe o que ele vai fazer com ela". Aproximamo-nos e começamos a conversar. Ele nos contou que é pedreiro e que está na rua por falta de emprego. O material que usava para trabalhar foi roubado - colher de pedreiro, trena, enxada, alicate. "(...) Não estou no ramo, porque não tenho as peças de trabalho". A coordenadora da pastoral fez uma lista do material que ele precisava para voltar a trabalhar. Comprometeu-se em conseguir o material. No final, o homem pede para o fotógrafo da Pastoral de Rua fazer uma foto dele com todos nós.

\section{Das outras artes de viver em situação de rua}

Arte produzida artesanalmente. Pessoas que vivem em situação de rua e produzem artesanato, tornando-se, assim, um meio de serem remuneradas. Em frente ao Hospital Geral encontramos Isaías, que produz agulhas de desentupir fogão e vende no bairro da feira. Com a venda das agulhas consegue apurar, em média, 10 reais por dia. Como Isaías, Rafael, 37 anos, natural de um munícipio do interior do Ceará, faz artesanato, como pulseiras, brincos, colares. Ele define-se como andarilho. De cidade em cidade Rafael vai vivendo, vivendo da arte que produz. O artesanato movimenta o corpo de Rafael.

Arte de "fazer de um tudo". Diego, o surfista espiritual, como ele mesmo se afirma, vive de tudo o que é serviço: capinar terrenos, ajudar pedreiro, fazer bicos como flanelinha...

Arte de "fazer arte" (crack, álcool...). Vemos essa arte de "fazer arte" como algumas histórias que encontramos de pessoas que usam álcool, crack ou outras drogas. A maioria delas já esqueceu os motivos que a levou ao uso e à dependência das substâncias e esqueceu, também, as tensões geradas a partir disso; assim, acaba reduzido ao uso de drogas o motivo pelo qual se encontra em situação de rua. Samaritana, embora não esteja com a família, demonstra preocupação com suas filhas. Afirma que deseja "deixar o vício", mas não consegue.

Arte como resistência política ativa. Mateus está há 15 anos em situação de rua. É pintor, trabalha

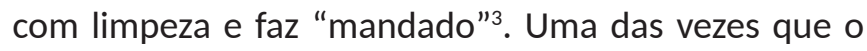
encontramos, estava chovendo. Perguntamos como era dormir na rua em dias de chuva: "(...) Quando chove, me cubro com um plástico e gosto de ficar ouvindo o 
barulho da chuva, sentindo os pingos". A relação estética (Bourriad, citado por Holzer \& Rauen, 2011; Rolnik, 2013; Virilo, 2011) de Mateus com a chuva. O som dos pingos que não ouvimos. A chuva banhando Mateus de possibilidades por ele inventadas. A arte de produzir uma relação de beleza com a vida. A arte de fazer arte a partir desses sutis gestos de encontro com a vida. Uma experiência do fora na realidade vivida (Levy, 2011). Mateus produz um novo processo de subjetivação acerca do modo de viver em situação de rua que nos remete à ética, porque resgatar a poesia dos hábitos cotidianos é inseparável do resgate de sua dignidade, essencial na cura da desqualificação causadora da intoxicação afetiva que enfraquece e imobiliza. Política, porque reativar a potência criadora da vida é resistir contra a humilhação, cujo efeito é exatamente miná-la. Uma resistência política que opera no invisível (p. 5).

Madalena, 51 anos, recusa-se a voltar para a sua cidade de origem. Seu corpo nega-se a sofrer. Ela é portadora de sofrimento psíquico e quando a encontramos, estava escrevendo e verbalizando alguns delírios, desorganizações e críticas. Ela é natural de uma cidade do interior do estado do Rio Grande do Norte e está há 10 anos em situação de rua. Já morou em outra capital. Ela mora no bairro da feira, na calçada de uma casa. A dona da casa sente no seu corpo o incômodo pela condição de vulnerabilidade em que se encontra Madalena. À noite, as duas conversam. Quando é noite de chuva, a vizinha chora a sorte de Madalena. "Apenas uma parede divide a gente", comenta a vizinha de Madalena. Sobre a relação com a vizinha, Madalena expressa - entre pensamentos, delírios e poesia:

Jesus Cristo é um palhaço. O rico é um louco. Desde pequena que o pai vê visão. Ele manda cercar tudo. Eu já passei de todos os ricos. (...) Só porque eu nasci de classe pobre... Eu vou aprender a voar. Toda terra está registrada em meu nome. Xuxa, a rainha, a terra toda é para ela, a papelada toda. A papelada que escrevi quer misturar, quer que eu case com ele para ficar com tudo.

A irmã Raquel questiona porque ela não volta para sua cidade natal. Madalena responde com a sua fraca saúde mental que resiste à morte do desejo: - "Você acha que a gente tem que ficar passando humilhação é?" E finaliza, respondendo a pergunta que lhe fizemos no início da conversa: "Acho ela [a vizinha] com muita paciência, em muitas calçadas mandaram me retirar." Ao escutarmos Madalena, pensamos que os paradigmas de submissão e conformismo que marcam as pessoas em situação de rua são postos em questionamento. Quando os noticiários colocam as pessoas em situação de rua como iguais, homogêneos, universais, apagam a potência da multiplicidade - que é justamente a potência da diferenciação da unha pontuda de cada pessoa que vive na rua - apagam as inúmeras máscaras de singularização que elas produzem, dobras na realidade como aquela que cartografamos nos processos de subjetivação de Madalena; mesmo sendo a esquizofrenia uma fuga da realidade, uma experiência da desrazão que não se configura como experiência do Fora (Pelbart, 2009).

As linhas de fuga correm sempre o risco de tornarem-se linhas de abolição, caindo nos buracos negros que engolem nossa vontade de potência. Pensando com Passos \& Benevides (2006): como evitar que uma linha de fuga se transforme em uma linha de abolição ou de autodestruição? A resposta é incerta e cabe a cada um experimentar, no seu corpo, a coragem de produzir essas linhas de fuga. Como nos alerta Lapoujade (2002) a questão não é estancar o sofrimento, mas encontrar uma saúde no sofrer, ou, em outras palavras, ser sensível ao sofrimento do corpo sem adoecer. Alguns personagens nômades experimentam essa estética de produzir bordados na densidade social da cidade. Alguns encontraram essa saúde, outros continuam bordando, aqui e acolá, suas linhas de fuga.

\section{Considerações nômades}

O processo de composição dessas paisagens psicossociais nômades nos afeta e nos convida a lançar um olhar ético, estético e político para as ruas e marquises da cidade. Em alguns lugares, as pessoas deixam suas esteiras, colchonetes, roupas e outas coisas penduradas nas árvores. Um museu aberto na rua. A exposição da vida do morador. Uma casa sem paredes, sem teto, sem vidro. Uma casa sem proteção. Uma casa. Hoje, nosso olhar para a cidade é outro. Olhamos as árvores das ruas, árvores guarda-roupas e dormitórios de quem faz da rua sua casa. Nos sinais de trânsito, reconhecemos as pessoas em situação de rua e lembramos suas histórias. Os acenos nos lembram que também fazemos parte da rua. Esse olhar sendo mudado, inclusive quando pensamos nesse modo de vida. Um olhar que vê não somente o sofrimento - como antes de iniciarmos a pesquisa - mas também amores, amizades, risos e respostas como a de Nicodemos. Perguntamos-lhe: como você está? E ele responde em meio a gargalhadas, segurando sua bicicleta e alisando a barba: "Tô vivendo... e tô gostando!". As pessoas que 
vivem a rua e na rua experimentam a potência de um espaço que se deforma pela ação de seus corpos que pisam, dormem, choram, fazem amor e reviram o sentido hegemônico desse espaço, produzindo um espaço vivido, um lugar para habitar na incerteza do trânsito de carros e corpos apressados.

Podemos perceber com essa cartografia que "tudo é político" e "que toda política é ao mesmo tempo macropolítica e micropolítica (Deleuze \& Guattari, 2012a, p. 99). Ás vezes, ao romper com as instituições e ao desejar permanecer ou não em situação de rua, "tem-se um porvir, não um devir" (Deleuze \& Guattari, 2012a, p. 73). O que caracterizaria o devir seria o nomadismo (Deleuze \& Guattari, 2012b) como gesto de pensar em movimento e agir para além e aquém do perambular pelas ruas e do se fixar num sexo, num gênero, numa família, num grupo étnico, numa identidade racial, numa cidade, numa praça, numa casa, numa feira, na calçada de um hospital, de uma loja ou de uma catedral. Nesta perspectiva, para viver um "modo de existência anônimo, a-subjetivo, não assujeitado" às instituições disciplinares e aos dispositivos da sociedade de controle (Pelbart, 2013, p. 261) a pessoa em situação de rua precisa agir, devir artista, produtor de saúde mental. Nós também precisamos agir no sentido que Ihe atribui Fernand Deligny (citado por Pelbart, 2013), para quem agir "é o gesto desinteressado, o movimento não representacional, sem intencionalidade, que consiste eventualmente em tecer [lugares], traçar [linhas de errância], pintar, no limite até mesmo em escrever..." (p. 261). Por isso, ao escrever a cartografia da experiência radical de viver em situação de rua, nós lutamos, quase em vão, contra a linguagem que "permite falar no lugar dos outros, pensar por eles, fazer com que sejam ou desapareçam, decidir o seu destino" (Pelbart, 2013, p. 261).

A arte de sobreviver "à crueldade de estar lançado no mundo sem trégua, perigo sempre eminente, tensão de um estado infindável de alerta, desassossego (Rolnik, 2013, p, 1), sem enlouquecer como efeito das tensões da cidade e da precariedade da vida em situação de rua é um modo de produzir resistência. Apostamos na arte relacional como dispositivo de produção de saúde mental e na escrita deste artigo como ensaio de superação da dicotomia saúde/saúde mental e dos binarismos que produzem uma redução epistemológica, interpretando saúde mental como o contrário de sofrimento psicológico, em geral, já diagnosticado pela psiquiatria como doença ou transtorno mental, associado ou não ao uso de medicalização e ao uso de substância psicoativas consideradas ilícitas. Portanto, desejamos contribuir com a defesa da saúde mental associada à determinação social da saúde, especialmente, às forças da vida e à capacidade de cuidar de si, reinventar-se mesmo em condições de esgotamento e de extrema vulnerabilidade. Segundo Canguilhem (citado por Lavrador, 2012):

Uma vida institui suas normas para se preservar e lutar contra os perigos que a ameaçam. Mas, ao mesmo tempo, também tende a expandir-se ao encarar os riscos e arriscar a própria vida. A concepção de saúde não tem nada a ver com a de estabilidade e nem tampouco com um assujeitamento às normas. Faz parte da saúde abusar da própria saúde, criando novas normas de vida que permitam que ela se expanda (pp. 412-413).

As afetações com o modo de viver e fazer arte das pessoas em situação de rua produziram diferença em nosso modo de fazer pesquisa. Essas pessoas nos apresentaram a vida, mostraram histórias. A cidade não é mais a mesma para nós e a população de rua também não é mais a mesma. Essa arte de viver o dia a dia nas ruas, de uma ou várias cidades, exige uma resistência política a partir da qual cada pessoa cria sua forma de arte para manter sua fraca saúde mental, como as formas de fazer arte que foram citadas anteriormente. A vida pode se tornar uma obra de arte, uma obra de arte pintada na resistência da produção de novos desejos, novas crenças, novas formas de associação. Outros territórios de existência se delineiam. Outras desterritorializações acontecerão.

\section{Referências}

Almeida, H. T.; Gouveia, A. C. B. F.; Medeiros, F. C.; Bezerra, F. S.; Bezerril, M. C. L.; Oliveira, V. D. F. C (2015). O centro de referência em direitos humanos e a população em situação de rua de $\operatorname{Natal}(R N)$ : a luta dos (in)visíveis urbanos. In I. L. de Paiva., C. de Souza., D. A. Valença \& A. Araújo (Orgs.), Direitos humanos e práxis experiências do $C R D H / R N$. (1 ${ }^{\text {a }}$ ed., pp. 8-313). Rio Grande do Norte: EDUFRN.

Barros, L. M. R. de, \& Barros, M. E. B. de (2014). O problema da análise em pesquisa cartográfica. In E. Passos, V. Kastrup \& S. Tedesco (Org.), Pistas do método da cartografia: a experiência da pesquisa e o plano comum (Vol. 2, pp. 175-202). Porto Alegre: Sulina Editora da UFRGS.

Barros, L. P. de; Kastrup, V. (2010). Cartografaré acompanhar processos. In E. Passos, V. Kastrup, \& L. Escóssia (Orgs.), Pistas do método da cartografia: Pesquisa-Intervenção e produção de subjetividade (pp. 52-75). Porto Alegre: Sulina.

Barros, R. B. de (2013). Grupo: a afirmação de um simulacro. Porto Alegre: Sulina Editora da UFRGS. 
Baptista, L. A. (1999). A cidade dos sábios. São Paulo: Summus.

Baudrillard, J. (1995). A Sociedade de Consumo. Lisboa: Edições 70.

Bosco, J., \& Blanc, A. (1975). De frente para o crime. [gravada por João Bosco]. In Caça à Raposa [Disco]. Brasil: RCA Victor.

Deleuze, G. (1976). Nietzsche e a filosofia (1 $1^{a}$ ed., E. F. Dias \& R. J. Dias, Trads.). Rio de Janeiro: Editora Rio. (Obra original publicada em 1962)

Deleuze, G. (2002). Espinosa: filosofia prática. (1ª ed., D. Lins \& F. P. Lins, Trads.). São Paulo: Escuta. (Obra original publicado em 1981)

Deleuze, G. (2005). Foucault. (1ª ed., P. E. Duarte, Trads.). Lisboa: Edições 70. (Obra original publicada em 1986)

Deleuze, G. (2011). Crítica e Clínica. (2 ${ }^{\mathrm{a}}$ ed., P. P. Pelbart, Trad.). São Paulo: Editora 34. (Obra original publicado em 1993)

Deleuze, G., \& Guattari, F. (2012a). Mil Platôs. (Vol. 3, 2ª ed., A. Guerra Neto, A. L. Oliveira, L. C. Leão \& S. Rolnik, Trads.). São Paulo: 34. (Obra original publicada em 1980)

Deleuze, G. \& Guattari, F. (2012b). Mil Platôs. (Vol. 5, 2ª ed., P. P. Pelbart \& J. Caifa, Trads.). São Paulo: 34. (Obra original publicada em 1980)

Foucault, M. (2010). Aula de 17 de março de 1976. In M. Foucault (Org.), Em defesa da sociedade: curso no Collège de France (1975-1976.). (2 $2^{\mathrm{a}}$ ed., pp. 201-222, M. E. A. P. Galvão, Trad.). São Paulo: WMF Martins Fontes. (Obra original publicada em 1997)

Gadotti, M. (1997). Prefácio. In M.S. S. Graciani (Org.), Pedagogia Social de Rua (pp. 11-17). São Paulo: Cortez.

Guattari, F. (2012). Caosmose: um novo paradigma estético. (2ª ed., A. L. Oliveira \& L. C. Leitão, Trad.). (Obra original publicada em 1992). São Paulo: 34

Holzer, D. C., \& Rauen, M. G. (2011). "A bondade de estranhos" de Mauricio lanes e a estética relacional. VOOS - Revista Polidisciplinar Eletrônica da Faculdade Guairacá, 3, 14-25.

Lancetti, A. (2009). Clínica peripatética. São Paulo: Editora Hucitec,

Lapoujade, D. (2002) O corpo não aguenta mais. In D. Lins, \& S. Gadelha (Orgs.), Nietzsche \& Deleuze: o que pode o corpo (pp. 81-90). Fortaleza: Secretaria da Cultura e do Desporto.

Levy, T. S. (2011). A Experiência do Fora: Blanchot, Foucault e Deleuze. Rio de Janeiro: Civilização Brasileira.

Lavrador, M. C.C.(2012). A psicologia e os desafios contemporâneos da reforma psiquiátrica. In A. M. Jacó- Vilela \& L. Sato (Orgs.), Diálogos em psicologia social [online] (pp. 408-419). Rio de Janeiro: Centro Edelstein de Pesquisas Sociais. Recuperado de SciELO Books $<$ http://books.scielo.org>

Mattos, R. M., \& Ferreira, R. F. (2004). Quem vocês pensam que (elas) são? Representações sobre as pessoas em situação de rua. Psicologia \&. Sociedade, 16(2), 47-58. doi: 10.1590/S010271822004000200007
Melo, T. H. A. G. (2011). A rua e a sociedade: articulações políticas, socialidade e a luta por reconhecimento da população em situação de rua (Dissertação de mestrado). Universidade Federal do Paraná, Curitiba, PR. Recuperado de http://www.humanas.ufpr.br/portal/antropologiasocial/files/2012/04/A-Rua-e-a-Sociedade-Melo-Completa2.pdf

Morais, N. A. de; Paludo, S., \& Koller, S. H. (2010). Famílias de crianças e adolescentes em situação de rua. In N. A. de Morais, L. Neiva-Silva, \& S. H. Koller (Orgs.), Endereço desconhecido: crianças e adolescentes em situação de rua (pp. 177-197). São Paulo: Casa do Psicólogo.

Noll, J. G. (2008). A fúria do Corpo. Rio de Janeiro: Record.

Pagot, A. M. (2012). O louco, a rua, a comunidade: as relações da cidade com a loucura em situação de rua. Rio de Janeiro: Fiocruz.

Passos, E., \& Benevides, B. (2006). Passagens da clínica. In A. Maciel, D. Kupermann. \& S. Tedesco (Orgs.), Polifonias: clínica, política e criação (pp. 89-100). Rio de Janeiro: Conreacapa.

Paugam, S. (1997). La disqualification sociale, essai sur la nouvelle pauvreté. Paris: Presses Universitaires de France.

Pelbart, P. P. (2009). Da Clausura do fora ao fora da clausura: loucura e desrazão. ( $2^{a}$ ed.) São Paulo: lluminuras

Pelbart, P. P. (2013). O avesso do niilismo: cartografias do esgotamento. São Paulo: N - 1 Edições.

Pozzana, L. (2014). A formação do cartógrafo é o mundo: corporificação e afetabilidade. In E. Passos, V. Kastrup \& S. Tedesco (Orgs.), Pistas do método da cartografia: a experiência da pesquisa e o plano comum (Vol. 2, pp. 42-65). Porto Alegre: Sulina Editora da UFRGS.

Rolnik, S. (2006). Cartografia Sentimental: transformações contemporâneas do desejo. Porto Alegre: Sulina, Editora da UFRGS.

Rolnik, S. (2013). Quarar a alma. Recuperado de: http://www.caosmose. net/suelyrolnik/pdf/quarar_a_alma.pdf

Santos, M. (2006). Por uma outra globalização: do pensamento único à consciência universal. Rio de Janeiro: Record.

Sawaia, B. B. (2008). As artimanhas da exclusão: análise psicossocial e ética da desigualdade social ( $8^{\mathrm{a}}$ ed.). Petrópolis: Vozes.

Silva, M. L. L. da. (2009). Trabalho e pessoas em situação de rua no Brasil. São Paulo: Cortez.

Varanda, W., \& Adorno, R. de C. F. (2004). Descartáveis urbanos: discutindo a complexidade da população de rua e o desafio para políticas de saúde. Saúde \& Sociedade, 13, 56-69. doi: 10.1590/ S0104-12902004000100007.

Virilio, P. (2011). Entrevista ao filósofo francês Paul Virilio. Recuperado de http://www.diarioliberdade.org/index.php?option=com_cont ent\&view=article\&id=16682:entrevista-ao-filosofo-frances-paul-virilio\&catid=99:batalha-de-ideias\&ltemid=113

\footnotetext{
${ }^{1}$ Por questões ético-políticas, optamos por não nomear as ruas, as paisagens e a cidade cartografadas e pelos mesmos motivos utilizaremos nomes fictícios para mantermos o sigilo das pessoas em situação de rua.

${ }^{2}$ Nome que Moisés usou para citar os cassetetes que os guardas particulares e policiais usam para fins de espancamento.

${ }^{3}$ Termo usado por ele para dizer do trabalho de fazer favores em troca de dinheiro ou outro ganho.
} 
Antônio Vladimir Félix-Silva, Doutor em Ciências Psicológicas pela Universidade de Havana (Cuba), é Professor dos cursos de Medicina e Psicologia da Universidade Federal do Piauí - UFPI e Membro co-fundador do Núcleo de Estudos e Pesquisas em Análise Institucional e Cartografia da Diferença, atuando com bases dos processos psicossociais da saúde, arte relacional, esquizoanálise e educação da diferença. Endereço para correspondência: Av. Capitão Claro, no 382. Centro - Parnaíba - PI, CEP:64200500. Telefone: (86)99915 9017. E-mail: wladyfelix@hotmail.com

Rita de Cássia Martins Sales, Psicóloga pela Universidade Potiguar (UnP), é Psicóloga colaboradora do Centro de Atenção Psicossocial (CAPS). São José de Mipibu - RN. E-mail: rita_cassia87@hotmail.com

Gabriela Pinheiro Soares, Psicóloga pela Universidade Potiguar (UnP), é Pós-graduanda em "Análise Institucional, Esquizoanálise

e Esquizodrama: Clínicas de Indivíduos, Grupos, Organizações e Redes Sociais" pela Fundação Gregório Baremblitt e Instituto Félix Guattari. E-mail: gabypsoares@hotmail.com 